\title{
Desafios para reinventar o ensino e perspectivas para o curso de graduação em enfermagem
}

O artigo, de caráter reflexivo, objetiva chamar a atenção para os desafios na educação do século 21 e, com base em conceitos de Boaventura de Sousa Santos, propõe perspectivas para repensar e reinventar o ensino. Ressalta múltiplas formas de aprendizagem com vistas a tecer fios para introduzir aspectos potencializadores dos modos de ensinar e aprender. Tem como ponto de partida reflexões que advêm do campo da enfermagem, mas estende-se aos demais de maneira geral. Conclui-se que as responsabilidades sociais, políticas, éticas e cidadãs necessitam atravessar a educação que se quer emancipadora, inclusiva e solidária.

Descritores: Ensino, Enfermagem, Educação Superior.

\section{Challenges to reinvent the teaching and perspectives to nursing graduation course}

The article, of reflexive character, aims to call the attention to the challenges of the XXI century education and, based on the concepts of Boaventura de Sousa Santos, it proposes perspectives to reinvent the teaching. It emphasizes multiple learning forms intending to weave threads to introduce positive aspects on the ways of teaching and learning. It has, as a starting point, reflections derived from the nursing field, but it which extends itself to the other fields in a general way. It ends up by inferring that the social, political, ethic and citizen responsibilities need to cross the education which wants itself liberating, inclusive and supportive.

Descriptors: Teaching, Nursing, Superior Education.

\section{Desafios para reinventar la enseñanza y perspectivas para el curso de graduación en enfermería}

El artículo de caracter reflexivo, tiene por objetivo, llamar la atención para los desafíos en la educación del siglo XXI y, con base en cenceptos de Boaventura de Souza Santos, propone perspectivas para repensar y reinventar la enseñanza. Resalta múltiple formas de aprendizaje con vistas a tejer hilos para introducir aspectos potencializadores de los modos de ensenar y aprender. Tiene como punto de partida reflexiones procedentes del campo de la enfermería pero extendese a los demás de una manera general. Se concluyeron que las responsabilidades sociales, políticas, éticas y ciudadanas necesitan atravesar la educación que se quiere emancipadora, inclusiva y solidaria.

Descriptores: Educación, Enfermería, Educación Superior.

\section{INTRODUÇÃO}

S em a pretensão de se constituir em síntese, mas com caráter provisório e aberto a novas incursões, o texto visa a destacar e discutir perspectivas para o ensino de graduação em enfermagem, sem, no entanto, se deter somente nesse intento. Para marcar o caminho, destacam-se desafios para o século 21, para a educação em especial e para a humanidade de modo geral.

Para começar a pensar o hoje e o amanhã dos cursos de graduação, à guisa de fundamentação, ressaltamse perspectivas de caráter teórico-metodológico que nos auxiliam a apontar os primeiros desafios específicos para o ensino de graduação em enfermagem.

Para continuar esse pensar atual e futuro da graduação em enfermagem, tecem-se reflexões sobre diferentes e complementares modos de aprender e ensinar, para então enumerar aspectos potencializadores desse processo.

\section{Desafios para o século 21}

O desafio da atualidade, para nós, educadores, em um mundo permeado pelo rompimento dos valores éticos da família e da sociedade, é resgatar o humanismo, os valores e a cultura, não rejeitando, no entanto, o progresso científico e técnico, mas zelando para que esse seja incorporado de forma harmônica na estrutura social e cultural. É imprescindível reconhecer, em todas as instâncias da educação, "o caráter indivisível da cultura em seus componentes históricos e científicos, emocionais e racionais, perceptivos e analíticos"(1:34).

Cuidar da Terra-Pátria é outro desafio para a humanidade,

1 Enfermeira. Doutora em ciências socioambientais. Professora adjunta IV da Universidade do Estado do Pará. Membro da comissão assessora da área de enfermagem do Inep. Mestre em educação.

2 Enfermeira. Doutora em enfermagem. Professora da Faculdade Católica Rainha do Sertão, Quixadá, CE. 
que necessita buscar confluências e tomar consciência da unidade da Terra, da unidade/diversidade da biosfera e do homem, do estatuto antropobiofísico e nosso estar aí. Uma nova comunidade que une, ao invés de separar, homem e natureza poderá pilotar e copilotar a Terra e, "ao mesmo tempo, a descoberta da comunidade de destino homem/ natureza dá responsabilidade telúrica ao homem. Sendo assim, é necessário abandonar radicalmente o projeto conquistador formulado por Descartes, Buffon, Marx. Não mais dominar a Terra, mas cuidar da terra doente, habitá-la, arrumá-la, cultivá-la"(2:186).

Sob esse entendimento, visa a contribuir com o ensino de graduação em enfermagem, para que ele aconteça considerando as dimensões locais, regionais e nacionais em sintonia com os desafios globais. Assim, passamos a pensar o hoje e o amanhã para então indicar perspectivas que fortaleçam a formação do futuro profissional.

\section{Para reinventar o ensino}

Para pensar o hoje e o amanhã dos cursos de graduação em enfermagem, iluminados pelo pensamento boaventuriano ${ }^{(3)}$, são propostas três perspectivas teóricometodológicas para os agentes do ensino de graduação em enfermagem: a sociologia das ausências (para revelar as experiências alternativas do hoje); a sociologia das emergências (para identificar as possibilidades e pistas do amanhã); e a teoria da tradução (para intermediar as trocas e a inteligibilidade entre os diferentes contextos em que ambas ocorrem). O que segue é, na verdade, um convite à leitura das novas proposições do autor e um conjunto de enunciações que poderão indicar rotas de diálogo sensíveis às múltiplas experiências nos cursos de graduação.

\section{A favor de uma razão que amplia o presente}

A razão moderna ocidental reivindica ser a única forma de racionalidade e não se presta a descobrir outros tipos; reivindica ser exclusiva, completa e universal, embora somente seja uma das lógicas de racionalidade que existe no mundo e só prevaleça nos estratos incluídos na modernidade ocidental. Não é possível aceitar a compreensão do mundo como maior do que a compreensão ocidental do mundo.

Partindo dessa premissa, para pensar o hoje dos cursos de graduação em enfermagem, propõem-se primeiramente procedimentos negados pela razão moderna ocidental: pensar as condições das dicotomias (teoria e prática, ensino e aprendizagem, estudo e trabalho, saúde e doença etc.), rever articulações de poder e revelar opções (ensino e pesquisa, ensino e extensão, tempo e espaço etc.) que foram obscurecidas pelas dicotomias hegemônicas.

Nesse sentido, uma das primeiras perspectivas para o ensino de graduação em enfermagem é a ampla socialização de experiências alternativas à razão reducionista, presentes em diferentes contextos deste imenso país. É preciso tornar visíveis experiências em desenvolvimento nos cursos que evidenciem estratégias de superação das dicotomias, propostas inovadoras curriculares que sinalizem novos mapas e/ou constelações com e entre os saberes, entre outras. Os espaços dos eventos de enfermagem podem ser ocupados com os relatos de experiências que imprimem um olhar sobre os cursos, que reinventam um fazer pedagógico, que ressignifiquem o ensinar e o aprender, constituindo, assim, um novo agir educativo.

\section{A favor de uma razão que contrai o futuro}

Por outro lado, se a razão moderna ocidental também estabelece uma visão do futuro e a direção da história reside em desenvolvimento e progresso ilimitados, logo, o futuro é infinito. Contrair os meios futuros para pensá-los como escassos e, consequentemente, objetos de estudo torna possível considerar o futuro como componente intrínseco do presente. Em outras palavras, a contração do futuro contribui para a expansão do presente.

Nesse contexto, outra perspectiva apontada para o ensino de graduação em enfermagem é a identificação das tendências e pistas, dos/nos projetos políticos pedagógicos, dos princípios do Sistema Único de Saúde (SUS) e dos conceitos reitores do Sistema Nacional de Avaliação da Educação Superior (Sinaes) que indiquem sinais de avanço, novas sensibilidades, outras relações/conexões, diferentes inclusões etc.

A sociologia das emergências é a investigação das opções contidas no horizonte de possibilidades concretas. Consiste em empreender uma amplificação simbólica de conhecimentos, práticas e agentes para identificar as tendências do futuro, nas quais é possível intervir para maximizar a probabilidade de esperança, bem como a possibilidade de frustração.

\section{A favor de uma teoria da tradução}

A tradução de conhecimentos e práticas (e de seus agentes) consiste em um trabalho de interpretação entre duas ou mais culturas/contextos para identificar preocupações iguais entre as mesmas e respostas diferentes que proveem delas. Portanto, deve ser o cruzamento de motivações com origem em culturas/contextos diferentes.

Só por meio da inteligibilidade mútua de práticas é possível avaliar e identificar prováveis alianças. O trabalho de tradução ocorre entre conhecimentos e culturas, por um lado, e práticas e agentes, por outro, enquanto, ao mesmo tempo, cria condições para emancipações sociais de grupos concretos em um presente, cuja injustiça é legitimada com base em um desperdício volumoso de experiência. $O$ trabalho de tradução revela ou denuncia a dimensão de tal desperdício. O tipo de transformação social que pode ser realizado com base no trabalho de tradução requer as constelações de significado criadas, para serem 
transformadas e mudar práticas. Para isso, ele deve ser completado pela prática de manifestos.

\section{Outras perspectivas possíveis}

Para continuar a pensar o hoje e o amanhã dos cursos de graduação em enfermagem, é importante, nesse contexto, rever a concepção de aprendizagem, refletindo/aprendendo seus princípios ${ }^{(4)}$, assim constituídos:

- aprendizagem consciente: o aprendiz como centro do processo, responsabilizando-se pela aprendizagem, participando, questionando, contribuindo e agindo como corresponsável pelo processo de formação;

- aprendizagem cooperativa: difusão coletiva que amplia os questionamentos e resultados, o que, por certo, contribui para a construção/reconstrução do conhecimento. Essa construção coletiva influencia na aprendizagem e na construção individual;

- aprendizagem continuada: diz respeito à aprendizagem ao longo da vida e que tem correlação direta com as experiências e com a própria consciência de cada sujeito/ aprendiz. Está atrelada às demandas de um mundo em constante evolução, em que as mudanças e os desafios são permanentes e exigem ação competente e hábil;

\section{- aprendizagem interdisciplinar:} possibilita aprender na realidade e, por meio dessa, intercambiar conhecimentos teoricamente já sistematizados, o que conduz a uma compreensão global e abrangente dessa realidade;

\section{- aprendizagem contextualizada: o}

aprendiz está sempre e minuciosamente ligado ao contexto em que a experiência é vivida. Há uma busca de aprender o que é significativo e conectado ao cotidiano do sujeito/ aprendiz e que diz respeito à superação e resolução de problemas práticos;

- aprendizagem significativa: há necessidade de compreensão do significado da aprendizagem e do sentido das informações. Essa é pautada nas condições de vinculação do novo conhecimento em construção com a bagagem cognitiva do sujeito/aprendiz, no material que deve possuir significado lógico e psicológico e, ainda, na disposição do indivíduo à aprendizagem, que pode ser circunstancial ou permanente;

- aprendizagem como síntese pessoal: é fruto da interação sujeito-objeto do conhecimento, mediada pela realidade, tratando-se, no entanto, de construção de síntese pessoal. Assim, tendo a aprendizagem um caráter ativo, é o resultado de uma construção pessoal, na qual estão inseridos o sujeito que aprende, os outros significativos e os agentes culturais.

Considerando os fios tecidos nas dimensões que nortearam a análise do olhar dos estudantes (física, social e pedagógica), destacamos alguns aspectos potencializadores do modo de ensinar e aprender, pois acreditamos que muitas fragilidades residam nesse processo e, por isso, diversas perspectivas precisam insistir nessa direção (para fazer sentido), tendo como referência a cultura e o local de inserção do curso e, como princípio norteador, a construção do conhecimento:

- diferentes dinâmicas nos espaços físicos para favorecer os encontros reforçando a ideia de "círculos de diálogos", para pensar o saber como fluido e fluxo de um movimento circular e dialógico: "Estamos destinados a aprender como uma atividade perene ao longo da vida, dentro e fora das estruturas e dos cenários da educação formal"(5:45). Nesse sentido, o saber não tem lugar fixo, ator principal e/ou língua oficial, mas é um entrelugar, entre e com todos, e que se traduz entre e com múltiplos signos e símbolos. Além do diálogo, fim do processo, há que se cuidar dos meios/recursos que estejam disponíveis (com quantidade e qualidade), que sejam efetivamente utilizados e, para isso, integrados aos processos intra e extraclasse. Não adianta dispor se não há estratégias mobilizadoras para o uso;

- a consulta como atividade científico-pedagógica, que deve, sem dúvida nenhuma, ser pautada em observação e investigação sobre o que se consulta, baseada em procedimentos, informações coerentes e sistemáticas, necessárias à clarificação do significado do objeto. Portanto, deve permear o ato educativo. A consulta se faz, assim, um princípio de pesquisa, princípio educativo e científico(6). Não se faz pesquisa sem consulta. Mas, para isso, é preciso saber consultar. A consulta não é uma atividade desconexa, mas intencional, que envolve os sujeitos ou um sujeito e um objeto, em interação objetivo-subjetiva. Nessa interação, os sujeitos apropriamse mutuamente do significado do objeto

e de si mesmos. $\mathrm{O}$ ato de consultar compreendido assim é fundamental na e para a construção do conhecimento. Sabemos que, uma vez que os sujeitos se apropriam da realidade, constroem referenciais de análise, interpretação de si e do mundo em que vivem. A consulta torna-se, então, atividade pedagógica necessária, visto que contribui para que o sujeito construa o conhecimento conforme se apropria de informações, subsídios e procedimentos fundamentais à compreensão da realidade. Esses referenciais, por sua vez, devem instigar a busca, a investigação, a reflexão, a análise, e não se constituírem em padrões extremamente rígidos, em fórmulas inalteradas, modelos fixos e conhecimentos acabados; - novos modos de distribuir o tempo, por conta do perfil que se revela e das inconsistências que se insinuam, diante das temporalidades flutuantes (estudantes com duplas jornadas, professores sem tempo de orientar). Como vamos construir existência nessas condições? A existência acontece quando o que há está situado dentro, entre e em algum tipo de relacionamento com A Teia da Existência ${ }^{(5: 21)}$ se constitui “nas, entre as e através das relações de troca que a cada momento se estabelecem, transformam e recriam tudo que envolve a realidade da vida". Podemos afirmar que existimos em função das trocas que produzimos em cada encontro educativo, em cada celebração, em cada entre vivido. Para 
aprender um saber, o indivíduo necessita fazer parte, estar entre, com e em uma comunidade-aprendente. "A unidade da aprendizagem não é cada pessoa tomada individualmente. Ela é a equipe, o grupo dialogante no momento em que algum conhecimento é vivido como uma experiência ativa de ensino-aprendizagem"(5). O outro/outra influi, colabora e participa do aprender, o verdadeiro "outro(a) coletivo", interativo, social e cultural. Enfim, é preciso pensar no tempo de orientação e desenvolvimento de competências de estudo na sala de aula "dentro daquele que é o contexto regular das aprendizagens escolares, que permite mexer na dinâmica pedagógica do mesmo e ajustar expectativas de respostas às ajudas educativas que efetivamente se prestam"(5:56). Cabe ao professor abrir espaço para discussão e reflexão com seus alunos sobre o ofício de aluno e tornar-se um motivador-orientador do saber;

- estratégias de ensino com tecnologias diversificadas (tecnologias duras, leveduras e leves). Tais intensidades referem-se às modalidades tecnológicas. "Uma vinculada a sua mão e na qual cabem, por exemplo, o estetoscópio, bem como o ecógrafo, o endoscópio, entre vários outros equipamentos que expressam uma caixa de ferramentas tecnológicas formada por 'tecnologias duras'; outra está em sua cabeça, na qual cabem saberes bem estruturados, como a clínica e a epidemiologia, que expressam uma caixa formada por tecnologias leve-duras; e, finalmente, a outra, presente no espaço relacional trabalhador-usuário, que contém tecnologias leves implicadas com a produção das relações entre dois sujeitos, que só tem materialidade em ato"(7). Na perspectiva do texto, o sujeito é o médico, que faz uso delas com o usuário para produzir saúde em ato. Fazendo uma analogia, podemos pensar no professor como sujeito, que faz uso delas com os estudantes para produzir aprendizagem em ato. É com esse sentido que apontamos tal perspectiva tridimensional;

- ressignificar a didática, pois, se o professor adota as tradicionais, os estudantes respondem com estratégias do tipo sincronia, fechamento, fragmentação, homogeneização, ou seja, mais de defesa do que de construção e organização. São consideradas didáticas tradicionais aquelas que alternam lições, exercícios e avaliações como texto do saber, em que o professor progride no texto que estabeleceu ou que recebeu já constituído e, ao longo do ano, vai dando conta por meio das lições;

- debater a cultura e discutir as novas identidades culturais na pós-modernidade. As velhas identidades, que por tanto tempo estabilizaram o mundo social, estão em declínio. Novas identidades estão surgindo, deixando o indivíduo moderno fragmentado ${ }^{(8)}$. O debate é relevante para os estudos culturais no campo da saúde e da enfermagem. A noção de híbridos culturais pode contribuir com os estudos nesses campos, tornando-os abertos aos fenômenos plurais e diversos que se manifestam nos respectivos saberes/fazeres dos sujeitos individuais e coletivos;

- há que se construir solidariedade visando ao processo de cuidar, que traga mais benefícios do que riscos, que não negue as instâncias do conhecimento cultural, mas que integre as determinações locais em estratégias de atenção. As interdependências poderão ampliar as independências e assim estabelecer uma dependência saudável e autônoma.

\section{Considerações finais}

À guisa de reflexão, podemos afirmar que esse não é o ponto de chegada, e sim o de partida. Por isso, o debate deve permanecer aberto, pois a educação é uma área dinâmica do conhecimento, que dá margem a muitos olhares, compreensão e interpretação.

Enfim, devemos estar cônscios das responsabilidades sociais-políticaséticas-cidadãs e nos comprometermos a continuar vigilantes e atuantes na luta por uma educação libertadora, emancipadora, inclusiva e solidária, que viabilize a formação de profissionais de saúde/enfermagem, capazes de atender à demanda social e intervir no processo saúde-doença de forma competente, ética, justa, sensível, igualitária e solidária. Devemos fazer valer a Constituição Federal Brasileira, os princípios do SUS, das Diretrizes Curriculares Nacionais (DCN) e do Sinaes e os aspectos éticos e legais do exercício da enfermagem.

\section{Referências}

1. Padoulos GS. Aprender para o século XXI. In: Delors J, organizador.

A educação para o século XXI: questões e perspectivas. Porto Alegre: Artmed; 2005.

2. Morin E. Terra-Pátria. Porto Alegre: Sulina; 1995.

3. Santos BS. Conhecimento prudente para uma vida decente. São Paulo: Cortez; 2005.

4. Eyng AM. A avaliação como estratégia na construção da identidade institucional. Raies. 2004;9(3):31-50.

5. Brandão CR. As sete cores. São Paulo: Cortez; 2006.

6. Demo P. Pesquisa, princípio científico e educativo. São Paulo:

Cortez; 1992.

7. Merhy EE. Um ensaio sobre o médico e suas valises tecnológicas: contribuições para compreender as reestruturações produtivas do setor saúde. Interface Comunic Saúde Educ. 2000;6(1):109-16.

8. Hall S. A identidade cultural na pós-modernidade. $10^{\mathrm{a}}$ ed. Rio de Janeiro: DP\&A; 2005 